\title{
LEARNING ABOUT THE INTERDEPENDENCE BETWEEN THE MACROECONOMY AND THE STOCK MARKET
}

\author{
FABIO MILANI
}

University of CALifornia, IRvine

\begin{abstract}
How strong is the interdependence between the macroeconomy and the stock market?

This paper estimates a New Keynesian general equilibrium model, which includes a wealth effect from asset price fluctuations to consumption, to assess the quantitative importance of interactions among the stock market, macroeconomic variables, and monetary policy.

The paper relaxes the assumption of rational expectations and assumes that economic agents learn over time and form near-rational expectations from their perceived model of the economy. The stock market, therefore, affects the economy through two channels: through a traditional "wealth effect" and through its impact on agents' expectations. Monetary policy decisions also affect and are potentially affected by the stock market.

The empirical results show that the direct wealth effect is modest, but asset price fluctuations have had important effects on output expectations. Shocks in the stock market can account for a large portion of output fluctuations. The effect on expectations, however, has declined over time.
\end{abstract}

Keywords: Stock Market, Wealth Channel, Monetary Policy, Constant-Gain Learning, Bayesian Estimation, Expectations.

JEL classification: E32, E44, E52, E58.

Date: May 15, 2008.

I would like to thank Efrem Castelnuovo for a very useful discussion and for comments, seminar participants at UC Irvine and at the Society for Nonlinear Dynamics and Econometrics 2008 conference in San Francisco for comments. Huy Pham provided excellent research assistance.

Address for correspondence: Department of Economics, 3151 Social Science Plaza, University of California, Irvine, CA 92697-5100. Phone: 949-824-4519. Fax: 949-824-2182. E-mail: fmilani@uci.edu. Homepage: http://www.socsci.uci.edu/ fmilani. 


\section{INTRODUCTION}

How strong are the links between the macroeconomy and the stock market?

The New Keynesian models that are widely employed to characterize the dynamics of output and inflation and to study monetary policy typically abstract from the stock market.

Asset prices, however, can influence the economy through a variety of channels. Policy discussions often emphasize the impact that asset price fluctuations can have on consumption spending decisions: this is the so-called "wealth effect". Monetary policy makers may consider actively responding to asset prices if the wealth channel is sizeable. But the size of the effect is still controversial: although most regressions that have been estimated in the literature show a positive and significant causal effect of wealth on consumption, ${ }^{1}$ recent studies conclude that the effect is smaller than previously thought (Lettau and Ludvigson, 2004, Case, Quigley, and Shiller, 2005). Additionally, asset prices can affect real activity trough other channels, such as through a Tobin's Q effect on investment and through a balance sheet/credit channel effect. ${ }^{2}$

Another central area of interdependence involves the link between asset prices and monetary policy decisions. Researchers have been interested in understanding both whether monetary policy responds to asset price fluctuations and how strongly the latter are affected by policy shocks (e.g., Rigobon and Sack, 2003, 2004, Bernanke and Kuttner, 2005, Biørnland and Leitemo, 2008) or other macroeconomic fundamentals (e.g., Chen et al., 1986).

This paper adopts a structural New Keynesian model, which will be estimated on U.S. data, to infer the strength of the interdependence among macroeconomic variables, monetary policy, and the stock market. The model, which is based on Nisticó (2005)'s extension of Blanchard (1985)'s overlapping generations framework, includes a wealth effect from asset prices to consumption, whose magnitude depends on a structural parameter, which affects the length of the households' planning horizon. Current output is affected by expectations of future output, real interest rates, and by current financial wealth, which is influenced by swings in stock prices. Current stock values depend on their own expected future values, on expectations about future real activity, and on the ex ante real interest rate.

\footnotetext{
${ }^{1}$ Research goes back to Ando and Modigliani (1963); Poterba (2000) and Davis and Palumbo (2001) are recent surveys.

${ }^{2}$ This paper will focus on the wealth channel; the Tobin's Q and balance sheet effects are, instead, omitted from the analysis.
} 
In modeling the expectations formation, the paper relaxes the traditional informational assumptions imposed by rational expectations and it assumes that agents form subjective near-rational - expectations and that they attempt to learn the model parameters over time.

Some critics of the conventional wealth channel effect have argued that changes in stock wealth mainly affect consumption through changes in expectations and consumer confidence, but no direct wealth effect exists. ${ }^{3}$ This paper includes both effects: a direct wealth effect of asset prices on consumption and output, and an effect of asset prices on future expectations. The estimation tries to empirically disentangle the two effects.

The model is estimated using Bayesian methods on monthly U.S. data. The constant gain coefficient is jointly estimated with the structural parameters of the economy, so that the learning process can be extracted from the data, rather than arbitrarily imposed.

1.1. Results. The empirical evidence suggests a small direct wealth effect of stock prices on output. Fluctuations in the stock market, however, affect economic agents' expectations of future real activity. The effect has considerably varied over the sample: in the first half, economic agents believed changes in the stock market to have a strong effect on output, while they revised their beliefs downward in the second part of the sample.

Through such effect on expectations, therefore, the stock market plays an important role for macroeconomic variables. In the 1960s-1970s, up to 60-70\% of fluctuations in the output gap were explained by shocks that originated in the stock market; the stock market also acted to amplify the transmission of monetary policy shocks. The importance of stock market shocks has declined over the sample: in the 1990s-2000s, they typically account for less than $20 \%$ of the variability in output. Fluctuations in the stock price gap were mainly driven by its own innovations until the 1970s, but they have been increasingly affected by demand shocks afterwards. Monetary policy shocks account for at most $10 \%$ of fluctuations in the stock market and their effect has also changed over time.

\footnotetext{
${ }^{3}$ Examples are Hymans (1970), who argues that stock market wealth has small effects on consumption after accounting for changes in consumer confidence, Otoo (1999), who shows that the relation between stock prices and consumer confidence is counterfactually similar between stock owners and non-owners, and Jansen and Nahuis (2003), who find that the short-run impact of changes in the stock market depends on their effect on perceptions about future real activity, rather than personal finances, as would be expected under a traditional wealth channel.
} 
The data show that the estimated response of monetary policy to the stock price gap has been positive if computed over the full sample. But monetary policy has reacted less to the stock market in the post-1984 sample. Moreover, post-1984 policy has responded to the stock market only to the extent that it affected output and inflation forecasts: when those forecasts are included in the policy rule, the estimated reaction to stock prices drops to zero.

1.2. Related Literature. This paper aims to contribute to the literature on the interaction between the stock market and macroeconomic variables. Their linkages have interested researchers for a long time (e.g., Fischer and Merton, 1985, for a discussion, Blanchard, 1981, for an early theoretical analysis), but empirical analysis in a general equilibrium setting are rare. The paper's main objective, therefore, is to offer quantitative estimates about the role of such linkages using a theory-based general equilibrium model.

The paper is closely related to the studies that seek to estimate the wealth effect (e.g., Poterba, 2000, Davis and Palumbo, 2001, Lettau and Ludvigson, 2004) and to those that analyze the interaction between asset prices and monetary policy from a positive or normative perspective (e.g., Rigobon and Sack, 2003, 2004, Biørnland and Leitemo, 2008, Bernanke and Gertler, 1999, 2001, Cecchetti et al., 2000, and Gilchrist and Leahy, 2002). This paper provides estimates of the wealth effect in a structural model, which permits to control for general equilibrium effects, and it reveals a quantitative important channel through which asset prices affect the economy and which operates through expectations. The paper also adds to the evidence on the interrelationship between monetary policy and asset prices, by showing that monetary policy has reacted to stock prices (but, after Volcker, not beyond their role as leading indicators), that stock prices are affected by policy shocks, and that both effects seem to have weakened over time.

Finally, the paper is related to the countless empirical studies using the New Keynesian model, as it hints that the typical omission of stock market variables may represent an important misspecification of the model, to the empirical studies that replace rational expectations with adaptive learning (e.g., Adam, 2005, Milani 2007, 2008, Orphanides and Williams, 2003, Primiceri, 2006), and to the studies that illustrate how learning can help in explaining asset price dynamics (e.g., Timmermann, 1993, Guidolin and Timmermann, 2007, Adam et al., 2007, and Branch and Evans, 2007). 


\section{A Model with Wealth Effects}

2.1. Households. The model is based on Nisticó (2005), who extends Blanchard (1985) and Yaari (1965)'s perpetual youth models to include risky equities and adapts it to a New Keynesian framework. ${ }^{4}$ An indefinite number of cohorts populate the economy. Each cohort may survive in any period with probability $(1-\gamma)$, which may be more generally interpreted as the probability of remaining active in the market. ${ }^{5}$

Each household of age $j$ maximizes the lifetime utility at time 0

$$
E_{0} \sum_{t=0}^{\infty} \beta^{t}(1-\gamma)^{t}\left[\zeta_{t} \log \left(C_{j, t}\right)+\log \left(1-N_{j, t}\right)\right]
$$

where $C_{j, t}$ denotes an index of consumption goods, $N_{j, t}$ indicates hours worked, and $\zeta_{t}$ is an aggregate preference shock. Consumers discount utility at the rate $0 \leq \beta \leq 1$, which denotes the usual intertemporal discount factor, and $1-\gamma$, where $0 \leq \gamma \leq 1$, to account for their limited lifespan. Consumers can invest in two types of financial assets: bonds and equity shares, which are issued by firms, to which they also supply labor. ${ }^{6}$ Their portfolio, therefore, consists of a set of state-contingent assets with payoff $B_{j, t+1}$ in $t+1$, which they discount using the stochastic discount factor $F_{t, t+1}$, and equity shares $Z_{j, t+1}(i)$ issued by firm $i$ at the real price $Q_{t}(i)$ and on which they receive dividends $D_{t}(i)$.

Consumers maximize (2.1) subject to a sequence of budget constraints

$$
P_{t} C_{j, t}+E_{t} F_{t, t+1}^{j} B_{j, t+1}+P_{t} \int_{0}^{1} Q_{t}(i) Z_{j, t+1}(i) d i \leq W_{t} N_{j, t}-P_{t} T_{j, t}+\Omega_{j, t}
$$

where $P_{t}$ is the aggregate price level, $\left(W_{t} N_{j, t}-P_{t} T_{j, t}\right)$ is net labor income, financial wealth $\Omega_{j, t}$ is given by

$$
\Omega_{j, t} \equiv \frac{1}{1-\gamma}\left[B_{j, t}+P_{t} \int_{0}^{1}\left(Q_{t}(i)+D_{t}(i)\right) Z_{j, t}(i) d i\right],
$$

and subject to a No-Ponzi-game condition

$$
\lim _{k \rightarrow \infty} E_{t}\left\{F_{t, t+k}^{j}(1-\gamma)^{k} \Omega_{j, t+k}\right\}=0
$$

\footnotetext{
${ }^{4} \mathrm{~A}$ sketch of the model is presented here; the reader is referred to Nisticó (2005) for a detailed step-by-step derivation.

${ }^{5}$ Therefore, $1 / \gamma$ can be interpreted as the households' time horizon when taking consumption and financial decisions. The size of the cohort remains fixed, since by assumption a fraction $\gamma$ of the total population is born and dies every period.

${ }^{6}$ The economy is "cashless" as in Woodford (2003).
} 
Financial wealth $\Omega_{j, t}$ not only includes the portfolio of contingent claims and equity shares, but also, following Blanchard (1985), the return on the insurance contract that redistributes among surviving cohorts the financial wealth of those that have exited the market. ${ }^{7}$

2.2. Firms. There are $i$ monopolistically-competitive firms in the economy, which produce a continuum of differentiated goods and set prices à la Calvo: therefore, only a fraction $0<1-\alpha<1$ of firms are allowed to set an optimal price in a given period. Firm $i$ is a monopolistic supplier of good $i$, which is produced according to the production technology $y_{t}(i)=A_{t} N_{t}(i)$, where $A_{t}$ is an exogenous aggregate technology shock and $N_{t}(i) \equiv \sum_{j=-\infty}^{t} \gamma(1-\gamma)^{t-j} N_{j, t}(i)$ is labor input, aggregated across cohorts. Firms face a common demand curve $y_{t}(i)=Y_{t}\left(\frac{p_{t}(i)}{P_{t}}\right)^{-\theta}$ for their product, where $Y_{t}$ is the aggregate output, given by $Y_{t}=\left[\int_{0}^{1} y_{t}(i)^{\frac{\theta-1}{\theta}} d i\right]^{\frac{\theta}{\theta-1}}$, where $\theta>1$ is the elasticity among differentiated goods. Each firm faces the same decision problem and, if allowed to re-optimize, sets the common price $p_{t}^{*}(i)$ to maximize the expected present discounted value of future profits:

$$
E_{t}\left\{\sum_{t=0}^{\infty} \alpha^{k} F_{t, t+k}\left[\Pi_{t+k}\left(p_{t}^{*}(i)\right)\right]\right\}
$$

where $\Pi_{t+k}(\cdot)$ denotes firm's nominal profits in period $t+k$.

2.3. Aggregate Dynamics. Log-linearization of the model first-order conditions around a zero-inflation steady state gives the following equations, which summarize the aggregate dynamics of the economy:

$$
\begin{aligned}
x_{t} & =\frac{1}{1+\psi} \widehat{E}_{t} x_{t+1}+\frac{\psi}{1+\psi} s_{t}-\frac{1}{1+\psi}\left(i_{t}-\widehat{E}_{t} \pi_{t+1}-r_{t}^{n}\right) \\
s_{t} & =\widetilde{\beta} \widehat{E}_{t} s_{t+1}+\lambda \widehat{E}_{t} x_{t+1}-\left(i_{t}-\widehat{E}_{t} \pi_{t+1}-r_{t}^{n}\right)+e_{t} \\
\pi_{t} & =\widetilde{\beta} \widehat{E}_{t} \pi_{t+1}+\kappa x_{t}+u_{t} \\
i_{t} & =\rho i_{t-1}+(1-\rho)\left[\left(1+\chi_{\pi}\right) \pi_{t-1}+\chi_{x} x_{t-1}+\chi_{s} s_{t-1}\right]+\varepsilon_{t}
\end{aligned}
$$

where $x_{t}$ denotes the output gap, $s_{t}$ denotes the real stock price gap, ${ }^{8} \pi_{t}$ denotes inflation, $i_{t}$ denotes the short-term nominal interest rate, and $\widehat{E}_{t}$ stands for subjective near-rational

\footnotetext{
${ }^{7}$ This is why financial wealth is multiplied by $\frac{1}{1-\gamma}$.

${ }^{8}$ The output gap is given by the deviation of total output $Y_{t}$ from $Y_{t}^{n}$, the natural level of output, i.e. the equilibrium level of output under flexible prices. Similarly the real stock price gap is defined as $s_{t} \equiv q_{t}-q_{t}^{n}$, where $q_{t}$ is the real stock price and $q_{t}^{n}$ is the corresponding flexible-price equilibrium level.
} 
expectations. ${ }^{9}$ Four disturbances affect the economy: $r_{t}^{n}$ denotes the natural rate of interest, $e_{t}$ is a shock that originates in the stock market and that can be rationalized as an equity premium shock (as done in Nisticó, 2005) or can account for fluctuations in asset prices that are not linked to fundamentals (e.g. bubbles, "irrational exuberance", fads, etc.), ${ }^{10} u_{t}$ is a cost-push shock, and $\varepsilon_{t}$ is a monetary policy shock.

Equation (2.6) represents the log-linearized intertemporal Euler equation that derives from the households' optimal choice of consumption. As in the standard optimizing IS equation in the New Keynesian model, the output gap depends on the expected one-period-ahead output gap and on the ex ante real interest rate. The novelty in the model is the inclusion of a wealth channel, i.e. a direct effect of stock price fluctuations on the output gap, which depends on the size of the reduced-form coefficient $\frac{\psi}{1+\psi}$. The coefficient $\psi$ is a combination of structural parameters, $\psi \equiv \gamma \frac{1-\beta(1-\gamma)}{(1-\gamma)} \frac{\Omega}{P C}$, where $\frac{\Omega}{P C}$ denotes the steady-state real financial wealth to consumption ratio. The magnitude of $\psi$ and hence the magnitude of the wealth effect positively depends on the structural parameter $\gamma$, which as seen in (2.1), denotes the span of the agents' planning horizon. A high survival probability - or equivalently a long planning horizon (i.e. a low $\gamma$ ) - implies a weaker wealth effect. Also, a shorter planning horizon reduces the degree of consumption smoothing and the responsiveness of consumption to the real interest rate.

The stock-price dynamics is characterized by equation (2.7). Stock prices are forwardlooking: the stock price gap depends on its own one-period ahead expectations, on expectations about future output gap, on the ex-ante real interest rate, and on the stock market shock. ${ }^{11}$

\footnotetext{
${ }^{9}$ As customary in the adaptive learning literature, near-rational expectations are assumed starting from the same log-linearized conditions that would be obtained under rational expectations.

${ }^{10}$ Learning may potentially generate endogenous bubbles in the model (e.g., Branch and Evans, 2008); the disturbance term $e_{t}$, however, captures exogenous bubbles that are not rationalized by such learning dynamics. Unmodeled changes in the stock market risk premium will also end up in $e_{t}$.

${ }^{11}$ In Nisticó (2005) and Airaudo, Nisticó, and Zanna (2007), the composite coefficient $\lambda \equiv\left(\frac{1+\varphi}{\mu-1}-1\right)$, which depends on the steady-state markup $\mu=\frac{\theta}{\theta-1}$ and on the inverse of the Frisch elasticity of labor supply $\varphi$, is negative: expectations of future expansions imply lower stock prices. This might be seen as contrary to what commonly thought and hinges on the assumption of a flexible labor market (which in the model would generate countercyclical profits and dividends, which is at odds with the evidence). In this paper, I assume marginal costs that can deviate from the value implied by the flexible labor market assumption, by allowing for labor rigidities as in Blanchard and Galí (2007). The coefficients $\lambda$ now becomes equal to $\left(\frac{(1-\delta)(1+\varphi)}{(\mu-1)}-1\right)$, which can be positive or negative, and where $(1-\delta)$ accounts for the rigidity. The relationship between marginal cost and the output gap is potentially attenuated. Although admittedly ad hoc, for the purposes
} 
Equation (2.8) is the forward-looking New-Keynesian Phillips curve. Inflation depends on expected inflation in $t+1$ and on current output gap. The parameter $\kappa$ denotes the slope of the Phillips curve and negatively depends on $\alpha$, the Calvo price stickiness parameter.

Equation (2.9) describes monetary policy. The central bank follows a Taylor rule by adjusting its policy instrument, a short-term nominal interest rate, in response to changes in inflation, output gap, and stock price gap. ${ }^{12}$ The policy feedback coefficients are denoted by $\chi_{t}^{\pi}, \chi_{t}^{x}$, and $\chi_{t}^{s}$, while $\rho$ accounts for interest-rate smoothing.

An advantage of this framework is that it permits to deal with interactions between macroeconomic variables and the stock market by maintaining a parsimonious structure, which potentially allows large wealth effects and nests the standard New Keynesian model as special case. ${ }^{13}$ The evidence from this paper can be seen as complementary to that coming from 'financial accelerator' models as in Bernanke, Gertler, and Gilchrist (1999) or Gilchrist and Saito (2007), which emphasize a different channel through which financial variables can affect the economy.

2.4. Expectations. The paper relaxes the assumption of rational expectations, by assuming that economic agents form near-rational expectations and learn about economic relationships over time (see Evans and Honkapohja, 2007, for a survey of the literature on learning models).

Agents are assumed to use a linear model as their Perceived Law of Motion

$$
Z_{t}=a_{t}+b_{t} Z_{t-1}+\epsilon_{t}
$$

where $Z_{t} \equiv\left[x_{t}, s_{t}, \pi_{t}, i_{t}\right]^{\prime}, a_{t}$ is a $4 \times 1$ vector and $b_{t}$ is a $4 \times 4$ matrix of coefficients. Agents are assumed not to know the relevant model parameters and they use historical data to learn them over time. Each period, they update their estimates of $a_{t}$ and $b_{t}$ according to the

of the paper, this assumption permits to avoid biases in the results that are due to imprecisions in modeling the labor market. A previous version of the paper, however, was estimated under flexible labor markets and delivered similar results.

${ }^{12}$ Monetary policy is assumed to react to the stock price gap, not to the level. This is similar to Nisticó (2005) and Gilchrist and Saito (2007). The estimation results remained comparable when policy responds to $s_{t}$ rather than to $s_{t-1}$.

${ }^{13}$ The model is mostly aimed at studying the influence of stock prices on the main macroeconomic variables that matter for monetary policy; the model, however, cannot provide the best possible characterization of stock price dynamics, since that would likely involve second-order terms, which are here lost in the linearization. 
constant-gain learning formula

$$
\begin{aligned}
\widehat{\phi}_{t} & =\widehat{\phi}_{t-1}+\overline{\mathbf{g}} R_{t}^{-1} X_{t}\left(Z_{t}-X_{t}^{\prime} \widehat{\phi}_{t-1}\right) \\
R_{t} & =R_{t-1}+\overline{\mathbf{g}}\left(X_{t} X_{t}^{\prime}-R_{t-1}\right)
\end{aligned}
$$

where (2.11) describes the updating of the learning rule coefficients collected in $\widehat{\phi}_{t}=\left(a_{t}^{\prime}, v e c\left(b_{t}\right)^{\prime}\right)^{\prime}$, and (2.12) characterizes the updating of the precision matrix $R_{t}$ of the stacked regressors $X_{t} \equiv\left\{1, x_{t-1}, s_{t-1}, \pi_{t-1}, i_{t-1}\right\}_{0}^{t-1}$. $\mathbf{g}$ denotes the constant gain coefficient. Economic agents are assumed to use only observables in their perceived model: they do not know, instead, the realizations of the unobservable shocks. ${ }^{14}$

\section{Estimation}

The vector $\Theta$ collects the coefficients that need to be estimated:

$$
\Theta=\left\{\gamma, \lambda, \kappa, \rho, \chi_{\pi}, \chi_{x}, \chi_{s}, \widehat{\mathbf{g}}, \rho_{r}, \rho_{e}, \rho_{u}, \sigma_{r}, \sigma_{e}, \sigma_{u}, \sigma_{\varepsilon}\right\}
$$

I use monthly data on industrial production, the S\&P 500 stock price index, the CPI, and the federal funds rate. The output gap $x_{t}$ is computed by detrending the log of the industrial production series using the Hodrick-Prescott filter. The real stock price gap $s_{t}$ is calculated as the S\&P 500 index deflated using the CPI and then detrended using the Hodrick-Prescott filter. ${ }^{15}$ Inflation $\pi_{t}$ is constructed as the monthly change in the CPI, and the Federal Funds rate $i_{t}$ is taken in levels and converted to monthly units. ${ }^{16}$ Figure 1 displays the output and stock price gap series. The stock price gap is about four times more volatile than the output gap. Booms and busts in the stock market anticipate economic expansions and recessions:

\footnotetext{
${ }^{14}$ Adding learning in the model results in a number of advantages. The relationship between stock prices and macroeconomic variables may have not been stable over time: learning allows the model to incorporate the time variation in a parsimonious way. As in Milani (2007), learning introduces lags in the model, without the need to change the microfoundations - by assuming habit formation in consumption or inflation indexation, for example - thereby helping in capturing the persistence in the data.

${ }^{15}$ Obviously, the empirical measures for the output and stock price gap obtained by detrending the data with the Hodrick-Prescott filter may not correspond to the theoretical definitions of deviations from their corresponding flexible price level. The flexible price potential stock price level in the model would be strictly connected to the flexible price potential output: I have preferred not to impose this restriction on the data and focus on a more data-driven decomposition.

${ }^{16}$ The series on industrial production, the CPI, and the Federal Funds rate were downloaded from FRED, the Federal Reserve Economic Database, hosted by the Federal Reserve Bank of St. Louis. Industrial production is the Industrial Production Index, Seasonally Adjusted (INDPRO), CPI is the Consumer Price Index for all Urban Consumers, All Items, Seasonally Adjusted (CPIAUCSL), the Federal Funds Rate is the Effective Federal Funds Rate, in percent, average of daily figures (FEDFUNDS). The S\&P 500 was downloaded from DRI.
} 
essentially all recessions in the sample have been preceded by a fall in the stock price gap (as known, however, not all stock market busts develop into a recession). The relation between the two series appears attenuated starting from the early 1980s (for instance, the cross-correlation between the output gap and the stock price gap lagged eight months goes from 0.66 in the pre-1979 sample to 0.13 in the post-1984 sample).

In the estimation, I consider a sample from 1960:M1 to 2007:M8. To initialize the learning algorithm in (2.11) and (2.12), I use pre-sample data from 1951:M1 to 1959:M1 (estimating (2.10) by OLS over this period).

The model is estimated by likelihood-based Bayesian methods to fit the output gap, real stock price gap, inflation, and Federal Funds rate series. The estimation technique follows Milani (2007), who extends the approach described in An and Schorfheide (2007) to permit the estimation of DSGE models with near-rational expectations and learning by economic agents. The results may depend on the assumed learning dynamics, if this is imposed $a$ priori. Therefore, here, I instead estimate also the learning process (which depends on the constant gain coefficient) jointly with the rest of structural parameters of the economy. In this way, the best-fitting learning process is extrapolated from the data along with the best-fitting preference and policy parameters.

I use the Metropolis-Hastings algorithm to generate draws from the posterior distribution. At each iteration, the likelihood is evaluated using the Kalman filter. I consider 300,000 draws, discarding the first $25 \%$ as initial burn-in.

The priors for the model parameters are described in Table 1. I assume a noninformative Uniform [0,1] prior for $\gamma$, the main parameter of interest, which affects the size of the wealth effect. I assume prior Gamma distributions for the slope of the Phillips curve $\kappa$ and for the monetary policy feedback coefficients to inflation and output gap. I assume, instead, a Normal prior with mean 0 and standard deviation 0.15 for the policy feedback to the stock price gap and with mean 0 and standard deviation 0.25 for $\lambda$. I also assume a Gamma prior distribution for the constant gain coefficient. Finally, Beta distributions are used for the autoregressive coefficients and Inverse Gamma distributions for the standard deviations of the shocks. ${ }^{17}$

\footnotetext{
${ }^{17}$ I need to fix some of the steady-state parameters that appear in the reduced-form coefficients: $\beta$ equals $\left(1+\frac{0.04}{12}\right)^{-1}=0.9967$, while the real financial wealth to consumption ratio in steady-state $\Omega$ is fixed to
} 


\section{Empirical Results}

Table 2 presents the posterior estimates for the baseline model, summarized by equations (2.6) to (2.9), with expectations formed using (2.10), (2.11), and (2.12). Table 3 displays the estimates for a selection of alternative cases. Table 4 and Figures 4 to 8 present the outcome of selected impulse response functions and variance decompositions, which are time-varying in the model as a consequence of learning dynamics.

4.1. How Large is the Wealth Effect? The data indicate a low value for the probability of exiting the market parameter $\gamma$. The mean posterior estimate equals 0.0084 , which implies a decision planning horizon of $1 / \gamma=119$ months, or 10 years. The implied wealth effect from changes in asset prices on output, measured by the composite reduced-form parameter $\frac{\psi}{1+\psi}$ is extremely small: the $95 \%$ highest posterior density interval does not contain values higher than 0.0025. The estimate for $\gamma$ implies that the degree of consumption smoothing and the sensitivity of output to the real interest rate remain high and close to the level they would assume in the nested case of a New Keynesian model with no wealth effect.

Turning to the other parameters, the posterior mean for the constant gain coefficient equals 0.014, which is lower, but not far from the value estimated in Milani (2007) on quarterly data. The sensitivity of the stock price gap to output expectations $\lambda$ has posterior mean 0.09 , but the estimate is characterized by large uncertainty (the $95 \%$ HPD contains values between -0.11 and 0.29$)$. The monthly Phillips curve is relatively flat $(\kappa=0.008)$.

The estimated autoregressive parameters for the shocks are moderate: this shows that learning can account for most of the persistence in the model, so that strongly seriallycorrelated exogenous shocks are not necessary.

4.1.1. Post-1984 Sample. The rate of equity ownership (direct or indirect through mutual funds) has doubled from below a quarter in the 1970s to more than half in the 1990s (see Duca, 2006). It is, therefore, possible that the size of the wealth effect has increased in the second part of the sample, since a larger fraction of the population can be now affected by swings in asset values. The estimates for the post-1984 sample (Table 3), however, indicate

4 (this value is consistent with the information in the Households Balance Sheet in the Federal Reserve System's Flow of Funds accounts). 
a posterior mean for $\gamma$ equal to 0.009 , which remains substantially at the same level as the full-sample result. ${ }^{18}$

When the model is estimated assuming that stock prices do not affect the formation of expectations, the posterior mean for $\gamma$, in the full sample case, becomes larger $(\gamma=0.033$, Table 3). The fit of the model, however, would be worse.

4.2. Evolving Economic Agents' Beliefs. Figure 2 illustrates the evolving beliefs by economic agents about the coefficient $b_{12, t}$, which refers to the perceived effect of stock prices on the output gap. Agents appear to use information in the stock market when forming expectations about future output: the effect on their expectations, however, declines over the sample.

Figure 3 provides some supportive evidence that such behavior is consistent with what a rational forecaster would do. Economic agents that use information in stock prices to forecast future output gaps obtain much lower root mean squared error in the early part of the sample and for most of the 1970s compared with forecasters that exclude asset prices from their perceived model. Their forecasting performances become very similar at the end of the sample (when, in fact, learning agents start to believe that stock prices have only a small effect on output). If agents had kept their initial belief of a large influence of the stock market on the economy, retaining their 1965 estimate of $b_{12}$ over the whole sample (that is $b_{12, t}=0.056$ for all $t$ 's), they would have done well until the $1970 \mathrm{~s}$, but poorly starting from 1985. This evidence is consistent with Stock and Watson (2003)'s finding that asset prices are useful in forecasting for some periods, but not others.

Turning to the other beliefs, I find that the intercept and the autoregressive parameter in the inflation equation are revised upward in the middle of the sample and decline again later on. The perceived degree of monetary policy inertia jumps after 1979. In the stock price equation, the perceived stock price persistence declines over time, while its sensitivity to the real interest rate is stronger in the late $1960 \mathrm{~s}$ and $1970 \mathrm{~s}^{19}$

\footnotetext{
${ }^{18}$ Estimates of the wealth effect appear stable over sub-samples. This finding differs from the evidence of sub-sample instability detected by Ludvigson and Steindel (1999), who estimate a much larger effect before 1985 than afterwards. Such instability may easily reflect changes in the impact of stock prices on expectations, more than a decline of the direct wealth effect over time.

${ }^{19}$ The full set of plots will be available in the online version of the paper at http://www.socsci.uci.edu/ fmilani/Stock.pdf.
} 
4.3. Do Stock Market Shocks Matter? As evidenced from the estimation, the direct wealth effect of short-run stock price changes on output is close to zero. Is the stock market hence irrelevant for output fluctuations?

In the model, asset prices affect the economy through a second effect, by leading economic agents to revise their expectations. This channel seems more important from the estimation, although the effect has varied over the sample. ${ }^{20}$

I investigate the importance of stock prices on the economy by looking at the variance decomposition over the sample. Figure 4 reports the percentage of variance in the output gap that is explained by shocks in the stock price gap variable, shown across forecast horizons (from one month to ten years) and over time.

Shocks in the stock market play a significant role in explaining output fluctuations. In several periods in the 1960s and 1970s, up to 60-70\% of output fluctuations are due to stock price shocks. The stock market appears to play a more limited role in the second half of the sample, the 1990s and 2000s: output fluctuations are due in large part to shocks in the natural interest rate and usually to less than $20 \%$ to stock market shocks. ${ }^{21}$

Figure 5 exhibits the impulse response of the output gap to a stock price shock as it varies over the sample. In the early part of the sample and until the early 1980s, stock market shocks induce a sharp increase in output that lasts about a year, before falling below its initial level and reverting to zero in less than three years. The effect becomes much smaller in the second half of the sample. Inflation is also affected by stock market shocks: the effect is larger in the 1970s (figure 6). These shocks explain, on average, around 10\% of the variance in inflation (Table 4 ).

Biørnland and Leitemo (2008) discuss how stock price shocks that produce a permanent effect on output may be interpreted as "news" shock, while shocks that produce only a transitory effect are more evocative of sunspot shocks. As them, I find only transitory effects

\footnotetext{
${ }^{20}$ The effect of stock prices through expectations, rather than through a direct wealth channel, is consistent with the microeconometric evidence that uncovers a similar consumption response between households that own or do not own equities to stock price changes (e.g., Otoo, 1999).

${ }^{21}$ Doan, Litterman, and Sims (2003), in a paper with unrelated focus, find similar evidence that stock price shocks are important in a structural VAR on data up to 1983. The percentage of variance they explain amounts to 30-40\% after 1960 and it was already declining from more than 60\% in their 1948:M7-1960:M1 sample.
} 
on output: these results seem to confirm, in a structural model, Biørnland and Leitemo's finding that stock price shocks may be better understood as non-fundamental sunspots.

But why has the role of stock market shocks faded over time?

One possible interpretation is that economic agents slowly learned over the sample and are converging to the true estimate of a wealth channel close to zero.

Maybe more likely, the decline in the stock market effects on the real economy may be related to the "Great Moderation". The standard deviation of the output gap measure has fallen from 2.68 before 1984 to 1.24 afterwards, while the standard deviation of the stock price gap did not experience a similar decline (it went from 8.61 to 6.60). The stock market has remained volatile, but the volatility of asset price fluctuations has not translated into macroeconomic volatility. The improved monetary policy, which is one of the major candidates as driver of the Great Moderation, may have induced agents to expect small deviations of output from potential and, therefore, it may have reduced the usefulness of asset prices in forecasting the output gap.

4.3.1. Stock Market and the Propagation of Shocks. The stock market, mainly through its effect on expectations, plays also a significant role in propagating non-financial shocks. Figure 7 displays the mean impulse responses, across sub-samples, of the output gap to a monetary policy shock for the baseline model and for an alternative model in which the effect of stock prices on expectations is shut down. In periods when economic agents give a relatively large weight to stock prices in their forecasting model, the stock market considerably amplifies the propagation of monetary policy shocks (this is evident in the 1960s and 1970s). A monetary contraction, in fact, depresses both output and stock prices, which in turn, through their effect on expectations, cause an even larger reduction in output. The initial effect is, therefore, magnified. The role of the stock market, however, varies over the sample. In the 1984-1999 sub-sample, the model that allows for stock price effects on expectations displays an attenuated and more transient response (this is mostly due to a perceived negative effect of past output on current stock prices in this period, which weakens the original output effect). Finally, when agents' beliefs assign a small weight to asset prices in their perceived law of motion (as in the 2000-2007 period), the impulse responses with or without stock price effects are virtually indistinguishable. 
If the stock market channel is entirely shut down, demand shocks would pick up most of the effect of stock price shocks in explaining output fluctuations (their importance rises to $60 \%$ in the first half and $75 \%$ in the second half). Monetary policy shocks would also matter more and they would account for a larger part of the variation in inflation.

4.4. Does Monetary Policy React to Stock Market Fluctuations? The full-sample estimates indicate that monetary policy has responded to the stock price gap. The posterior mean estimate for $\chi_{s}$ in table 2 equals 0.139 .

The feedback to the stock price gap is much lower $\left(\chi_{s}=0.034\right)$ in the post-1984 sample: this is consistent with the reduced influence of stock prices on output expectations and with the common perception that Fed's policy under Greenspan did not react to the bubble in the 1990s. Moreover, if the estimation is repeated using a Taylor rule that responds to forecasts of inflation and the output gap (i.e., to $\widehat{E}_{t} \pi_{t+1}$ and $\widehat{E}_{t} x_{t+1}$, assuming that the Fed uses the same forecasting model (2.10) as the private sector), rather than to their lagged values, the response to the stock price gap is quite precisely estimated around zero (and the model fit improves). This signals that policy reacts to stock prices only to the extent that they act as leading indicators of future inflation and real activity, but no separate response exists. ${ }^{22}$

Recent papers find that if central banks react to asset prices, they may increase the chances of indeterminacy in the economy. Carlstrom and Fuerst (2007) find determinacy only if the response to asset prices remains below a certain threshold. Airaudo et al. (2007), in the same model used in this paper, study determinacy and learnability conditions. They similarly show that a positive reaction to the stock price gap may enlarge the indeterminacy region. Indeterminacy is also more likely when $\gamma$ is close to 0 , as estimated in this paper.

The post-1984 estimates, however, indicate that Federal Reserve policy, by not actively targeting stock prices, has likely been conducive to determinacy and E-stability.

\subsection{The Effect of Monetary Policy and Macro Shocks on Stock Prices. Figure 8} presents the impulse responses of the stock price gap to one-standard-deviation monetary policy, demand, and supply shocks. Stock prices seem more responsive to monetary policy surprises in the 1960-1970s: a contractionary shock leads to a decline in stock prices with a

\footnotetext{
${ }^{22}$ Fuhrer and Tootell (2008) similarly find little evidence of an independent response to stock values when Greenbook forecasts are included in Taylor rules.
} 
negative peak seven months after the shock. The decline would be even more pronounced if examined on 1970s data alone. The response in the latest part of the sample, instead, is much smaller (the plotted response, however, conceals some variation that exists in the post-1984 period). ${ }^{23}$ This may suggest a recent more limited effect of monetary policy, but it might also reflect the difficulty in identifying monetary policy shocks in the second part of the sample on monthly data (responses that may be found on high-frequency data may have become extremely short-lived and may be lost in the monthly averaging).

Shocks in the natural interest rate lead to an immediate jump in the stock price gap, which turns negative after six-eight months, before reverting to zero. Inflationary shocks lead to a decline in the stock price gap, with a less sluggish adjustment in the post-1984 sample.

Table 4 reports the outcome of the forecast error variance decomposition at alternative horizons. Regarding the stock price gap, in the 1960-1970s, monetary policy shocks accounted for up to $7.5 \%$ of the variance, demand shocks for $6.2 \%$. Fluctuations in the stock market are mostly driven by shocks that originate in the stock market. In the second half of the sample, monetary policy shocks account for up to $9.7 \%$ of fluctuations, and demand shocks for more than 20\%: the stock market hence appears not as isolated from the rest of the economy as in the past.

\section{Conclusions}

The paper has provided evidence from a structural model on the empirical relevance of interactions between macroeconomic variables and the stock market. One of the main channels that are usually emphasized in policy discussions, the wealth channel, appears modest. But the stock market plays a significant role through its impact on expectations about future real activity.

Monetary policy seems to have reacted to stock price fluctuations, but, in the post-1984 sample, only to the extent that they influence output and inflation forecasts. A monetary policy response may be justified if non-rational movements in the stock market affect expectations, as found in the data, and if non-fundamental stock market shocks are an important source of fluctuations. But both these effects are now less important. Still, the welfare

\footnotetext{
${ }^{23}$ The small response may be consistent with Davig and Gerlach (2007)'s estimate of a distinct regime in the late 1990s-early 2002, in which stock prices' response to policy shocks is insignificant and volatile.
} 
implications of different monetary policy rules in a model in which asset prices affect private sector's expectations and learning is an important topic that deserves future study.

The stock market dynamics is affected by macroeconomic fundamentals, but a large part of fluctuations is due to non-fundamental stock price shocks. A better modeling of the stock market, which retains second-order terms, will be needed to shed more light on the nature of financial shocks (Challe and Giannitsarou, 2007, offer a general equilibrium framework in this direction). Future extensions should also move away from the linear/Gaussian framework: including stochastic volatility in the structural innovations, for example, would allow researchers to study the relation between output and stock price volatility, as well as between expectations of future booms and busts and volatility. Finally, it is necessary to check whether the evidence is robust to the use of a larger model and the inclusion of different financial sector channels: in this respect, Christiano et al. (2008)'s findings, in a different framework, similarly identify an important role for financial shocks. 


\section{REFERENCES}

[1] Adam, K., (2005). "Learning to Forecast and Cyclical Behavior of Output and Inflation", Macroeconomic Dynamics, Vol. 9(1), 1-27.

[2] Adam, K., A. Marcet, and J.P. Nicolini, (2007). "Stock Market Volatility and Learning", CEPR Working Paper No. 6518.

[3] Airaudo, M., S. Nisticó, and L.F. Zanna (2007), "Learning, Monetary Policy, and Asset Prices", LLEE Working Paper No.48.

[4] An, S., and F. Schorfheide, (2007). "Bayesian Analysis of DSGE Models", Econometric Reviews, Vol. 26, Iss. 2-4, 113-172.

[5] Ando, A., and F. Modigliani, (1963). "The 'Life Cycle' Hypothesis of Saving: Aggregate Implication and Tests, American Economic Review, 53(1), pp. 5584.

[6] Bernanke, B., and M. Gertler, (2001). "Should Central Banks Respond to Movements in Asset Prices?", American Economic Review, 253-57.

[7] Bernanke, B.S., and M. Gertler, and Gilchrist, S. (1999). "The Financial Accelerator in a Quantitative Business Cycle Framework," Handbook of Macroeconomics, edition 1, volume 1, chapter 21, 1341-1393.

[8] Bernanke, Ben S. and Kenneth N. Kuttner (2003), What Explains the Stock Markets Reaction to Federal Reserve Policy?", Journal of Finance, 60, 1221-1257.

[9] Bjørnland, H.C., and K. Leitemo, (2008). "Identifying the Interdependence between US Monetary Policy and the Stock Market", Journal of Monetary Economics, forthcoming.

[10] Blanchard, O.J., (1981). "Output, the Stock Market, and Interest Rates," American Economic Review, vol. 71(1), pages 132-43.

[11] Blanchard, O.J., (1985), "Debt, Deficits, and Finite Horizons", Journal of Political Economy, 93, pp. 223-247.

[12] Blanchard, O.J., and J. Galí, (2007). "The Macroeconomic Effects of Oil Price Shocks: Why are the 2000s so Different from the 1970s?", NBER Working Paper No. 13368.

[13] Branch, W., and G.W. Evans, (2007). "Asset Return Dynamics and Learning", mimeo, UC Irvine and University of Oregon.

[14] Branch, W., and G.W. Evans, (2008). "Learning about Risk and Return: A Simple Model of Bubbles and Crashes", mimeo, UC Irvine and University of Oregon.

[15] Carlstrom, C.T., and T.S. Fuerst, (2007). "Asset Prices, Nominal Rigidities, and Monetary Policy", Review of Economic Dynamics, vol. 10(2), 256-275.

[16] Case, K.E., J.M. Quigley, and R.J. Shiller (2005), "Comparing Wealth Effects: The Stock Market Versus The Housing Market", Advances in Macroeconomics, vol. 5(1).

[17] Cecchetti S G, H Genberg, J Lipsky and S Wadhwani, (2000). "Asset Prices and Central Bank Policy", Geneva Reports on the World Economy, vol 2, Geneva: International Center for Monetary and Banking Studies, London: Centre for Economic Policy Research.

[18] Challe, E., and C. Giannitsarou, (2007). "Stock Prices and Monetary Policy Shocks: a General Equilibrium Approach", unpublished manuscript.

[19] Chen, N.F., Roll, R., and S.A. Ross, (1986). "Economic Forces and the Stock Market," Journal of Business, vol. 59(3), pages 383-403.

[20] Christiano, L., Motto, R., and M. Rostagno, (2008). "Financial Factors in Business Cycles", unpublished manuscript.

[21] Davig, T., and J.R. Gerlach, (2006). "State-Dependent Stock Market Reactions to Monetary Policy", International Journal of Central Banking, Vol. 2(4), 65-84.

[22] Davis, M., and M.G. Palumbo (2001), "A Primer on the Economics and Time Series Econometrics of Wealth Effects", Federal Reserve Board Finance and Economics Discussion Series No. 09.

[23] Doan, T., Litterman, R., and C.A. Sims, (1983). "Forecasting and Conditional Projection Using Realistic Prior Distributions", Econometric Reviews, 3(1), 1-100.

[24] Duca, J.V., (2006). "Mutual Funds and the Evolving Long-Run Effects of Stock Wealth on U.S. Consumption", Journal of Economics and Business, 58(3), 202-221. 
[25] Evans, G.W., and S. Honkapohja, (2007). "Expectations, Learning and Monetary Policy: An Overview of Recent Research", Bank of Finland Discussion Paper No. 32.

[26] Fischer, S., and R.C. Merton, (1984). "Macroeconomics and Finance: the Role of the Stock Market," Carnegie-Rochester Conference Series on Public Policy, vol. 21, 57-108.

[27] Fuhrer, J., and G. Tootell, (2008). "Eyes on the prize: How did the Fed respond to the stock market?", Journal of Monetary Economics, forthcoming.

[28] Gilchrist, S., and J.V. Leahy, (2002). "Monetary Policy and Asset Prices", Journal of Monetary Economics, Vol. 49, Iss. 1, 75-97.

[29] Gilchrist, S., and M. Saito, (2007). "Expectations, Asset Prices and Monetary Policy: The Role of Learning", Asset Prices and Monetary Policy, ed. by John Campbell, Chicago: University of Chicago Press, forthcoming.

[30] Guidolin, M., and A. Timmermann, (2007). "Properties of Equilibrium Asset Prices Under Alternative Learning Schemes", Journal of Economic Dynamics and Control, vol. 31, issue 1, 161-217.

[31] Hymans, S., (1970). "Consumer durable spending: Explanation and prediction", Brookings Papers on Economic Activity, 2, pp. 173206.

[32] Jansen, J.W. and J.N. Nahuis (2003), "The Stock Market and Consumer Confidence: European Evidence", Economics Letters, 79, pp. 89-98.

[33] Lettau, M., and S. Ludvigson, (2004). "Understanding Trend and Cycle in Asset Values: Reevaluating the Wealth Effect on Consumption", American Economic Review, 94(1): 276-299.

[34] Ludvigson, S., and C. Steindel, (1999). "How Important is the Stock Market Effect on Consumption?," Economic Policy Review, Federal Reserve Bank of New York, July, pages 29-51.

[35] Milani, F., (2007). "Expectations, Learning and Macroeconomic Persistence", Journal of Monetary Economics, Vol. 54, Iss. 7, Pages 2065-2082.

[36] Milani, F., (2008). "Learning, Monetary Policy Rules, and Macroeconomic Stability", Journal Economic Dynamics and Control, forthcoming.

[37] Nistico', Salvatore. (2005) "Monetary Policy and Stock-Price Dynamics in a DSGE Framework." LLEE Working Document, 28, Luiss University.

[38] Orphanides, A., and J. Williams, (2003). "Imperfect Knowledge, Inflation Expectations and Monetary Policy", in Ben Bernanke and Michael Woodford, eds., Inflation Targeting. Chicago: University of Chicago Press.

[39] Otoo, M.W. (1999), "Consumer Sentiment and the Stock Market", Federal Reserve Board Finance and Economics Discussion Series No. 60.

[40] Poterba, J. (2000), "Stock Market Wealth and Consumption", Journal of Economic Perspectives, 14(2), pp. 99-119.

[41] Rigobon, R., and B. Sack, (2003). "Measuring the Reaction of Monetary Policy to the Stock Market," The Quarterly Journal of Economics, vol. 118(2), pages 639-669.

[42] Rigobon, R., and B. Sack, (2004). "The Impact of Monetary Policy on Asset Prices," Journal of Monetary Economics, vol. 51(8), pages 1553-1575.

[43] Stock, J.H, and M.W. Watson, (2003). "Forecasting Output and Inflation: The Role of Asset Prices,", Journal of Economic Literature, vol. 41(3), pages 788-829.

[44] Timmermann, A.G, (1993). "How Learning in Financial Markets Generates Excess Volatility and Predictability in Stock Prices," The Quarterly Journal of Economics, vol. 108(4), 1135-45.

[45] Woodford, M., (2003). Interest and Prices: Foundations of a Theory of Monetary Policy. Princeton: Princeton University Press.

[46] Yaari, Menahem E. (1965) "Uncertain Lifetime, Life Insurance, and the Theory of the Consumer." Review of Economic Studies, 32. 


\begin{tabular}{|l|c|l|l|c|c|}
\hline \hline & & \multicolumn{4}{|c|}{ Prior Distribution } \\
\hline Description & Parameter & Distr. & Support & Prior Mean & 95\% Prior Prob. Interval \\
\hline Prob. of Leaving the Mkt. & $\gamma$ & $U$ & {$[0,1]$} & 0.5 & {$[0.025,0.975]$} \\
Elast. Subst. Different. Goods & $\theta$ & $\Gamma$ & $\mathbb{R}^{+}$ & 12 & {$[3.26,26.13]$} \\
Slope PC & $\kappa$ & $\Gamma$ & $\mathbb{R}^{+}$ & 0.25 & {$[0.03,0.70]$} \\
MP Inertia & $\rho$ & $B$ & {$[0,1]$} & 0.8 & {$[0.459,0.985]$} \\
MP Inflation feedback & $\chi_{\pi}$ & $\Gamma$ & $\mathbb{R}^{+}$ & 0.5 & {$[0.06,1.40]$} \\
MP Output Gap feedback & $\chi_{x}$ & $\Gamma$ & $\mathbb{R}^{+}$ & 0.25 & {$[0.03,0.70]$} \\
MP Stock Price Gap feedback & $\chi_{s}$ & $N$ & $\mathbb{R}$ & 0 & {$[-0.29,0.29]$} \\
Std. Demand Shock & $\sigma_{r}$ & $\Gamma^{-1}$ & $\mathbb{R}^{+}$ & 0.11 & {$[0.038,0.31]$} \\
Std. Stock Price Shock & $\sigma_{e}$ & $\Gamma^{-1}$ & $\mathbb{R}^{+}$ & 0.33 & {$[0.11,0.92]$} \\
Std. Supply Shock & $\sigma_{u}$ & $\Gamma^{-1}$ & $\mathbb{R}^{+}$ & 0.11 & {$[0.038,0.31]$} \\
Std. MP Shock & $\sigma_{\varepsilon}$ & $\Gamma^{-1}$ & $\mathbb{R}^{+}$ & 0.11 & {$[0.038,0.31]$} \\
Autoregr. coeff. $r_{t}^{N}$ & $\rho_{r}$ & $B$ & {$[0,1]$} & 0.8 & {$[0.459,0.985]$} \\
Autoregr. coeff. $e_{t}^{N}$ & $\rho_{e}$ & $B$ & {$[0,1]$} & 0.8 & {$[0.459,0.985]$} \\
Autoregr. coeff. $u_{t}$ & $\rho_{u}$ & $B$ & {$[0,1]$} & 0.8 & {$[0.459,0.985]$} \\
Constant Gain & $\mathbf{g}$ & $\Gamma$ & $\mathbb{R}^{+}$ & 0.031 & {$[0.003,0.087]$} \\
\hline \hline
\end{tabular}

Table 1 - Prior Distributions.

( $U=$ Uniform, $N=$ Normal, $\Gamma=$ Gamma, $B=$ Beta, $\Gamma^{-1}=$ Inverse Gamma $)$ 


\begin{tabular}{|c|c|c|c|}
\hline & & \multicolumn{2}{|c|}{ Posterior Distribution } \\
\hline Description & Parameter & Posterior Mean & $95 \% \mathrm{HPD}$ \\
\hline Prob. of Leaving the Mkt. & $\gamma$ & $\begin{array}{c}0.0084 \\
(0.006)\end{array}$ & {$[0.0004,0.023]$} \\
\hline Sensit. Stock Prices to Output & $\lambda$ & $\begin{array}{r}0.09 \\
(0.10)\end{array}$ & {$[-0.11,0.29]$} \\
\hline Slope PC & $\kappa$ & $\begin{array}{l}0.008 \\
(0.004)\end{array}$ & {$[0.001,0.017]$} \\
\hline MP Inertia & $\rho$ & $\begin{array}{l}0.986 \\
(0.004)\end{array}$ & {$[0.977,0.994]$} \\
\hline MP Inflation feedback & $1+\chi_{\pi}$ & $\begin{array}{l}1.39 \\
(0.20)\end{array}$ & {$[1.11,1.91]$} \\
\hline MP Output Gap feedback & $\chi_{x}$ & $\begin{array}{l}0.19 \\
(0.09)\end{array}$ & {$[0.05,0.43]$} \\
\hline MP Stock Price Gap feedback & $\chi_{s}$ & $\begin{array}{l}0.135 \\
(0.05)\end{array}$ & {$[0.06,0.265]$} \\
\hline Std. Demand Shock & $\sigma_{r}$ & $\begin{array}{l}0.76 \\
(0.02)\end{array}$ & {$[0.71,0.80]$} \\
\hline Std. Stock Price Shock & $\sigma_{e}$ & $\begin{array}{l}4.15 \\
(0.13)\end{array}$ & {$[3.90,4.42]$} \\
\hline Std. Supply Shock & $\sigma_{u}$ & $\begin{array}{l}0.22 \\
(0.01)\end{array}$ & {$[0.21,0.24]$} \\
\hline Std. MP Shock & $\sigma_{\varepsilon}$ & $\begin{array}{l}0.045 \\
(0.001)\end{array}$ & {$[0.04,0.05]$} \\
\hline Autoregr. coeff. $r_{t}^{N}$ & $\rho_{r}$ & $\begin{array}{l}0.43 \\
(0.04)\end{array}$ & {$[0.35,0.50]$} \\
\hline Autoregr. coeff. $e_{t}$ & $\rho_{e}$ & $\begin{array}{l}0.24 \\
(0.04)\end{array}$ & {$[0.16,0.32]$} \\
\hline Autoregr. coeff. $u_{t}$ & $\rho_{u}$ & $\begin{array}{l}0.21 \\
(0.04)\end{array}$ & {$[0.13,0.28]$} \\
\hline Constant Gain & $\overline{\mathbf{g}}$ & $\begin{array}{c}0.014 \\
(0.0014)\end{array}$ & {$[0.011,0.017]$} \\
\hline Wealth Effect & $\frac{\psi}{1+\psi}$ & $\begin{array}{c}0.00055 \\
(0.0007)\end{array}$ & {$[0.000005,0.0025]$} \\
\hline
\end{tabular}

Table 2 - Posterior Estimates.

Full Sample 1960:M1-2007:M7, Baseline Case. The table shows the posterior mean (standard deviation in brackets) and the $95 \%$ Highest Posterior Density Interval. 


\begin{tabular}{|c|c|c|c|c|c|c|}
\hline & \multicolumn{2}{|c|}{ Post-1984 Sample } & \multicolumn{2}{|c|}{ Taylor rule with Expect. } & \multicolumn{2}{|c|}{ No Effect of $s_{t}$ on Expect. } \\
\hline Parameter & Post. Mean & $95 \% \mathrm{HPD}$ & Post. Mean & $95 \%$ HPD & Post. Mean & $95 \%$ HPD \\
\hline$\gamma$ & $\begin{array}{c}0.0090 \\
(0.007)\end{array}$ & {$[0.0004,0.026]$} & $\begin{array}{l}0.0090 \\
(0.007)\end{array}$ & {$[0.0004,0.024]$} & $\begin{array}{l}0.033 \\
(0.016)\end{array}$ & {$[0.002,0.062]$} \\
\hline$\lambda$ & 0.095 & {$[-0.30,0.48]$} & $\begin{array}{l}0.09 \\
(020)\end{array}$ & {$[-0.29,0.45]$} & 0.055 & {$[-0.15,0.27]$} \\
\hline$\kappa$ & $\begin{array}{l}0.012 \\
(0.007)\end{array}$ & {$[0.002,0.03]$} & $\begin{array}{l}0.013 \\
(0.007)\end{array}$ & {$[0.002,0.03]$} & $\begin{array}{l}0.0096 \\
(0.005)\end{array}$ & {$[0.0017,0.02]$} \\
\hline$\rho$ & $\begin{array}{l}0.989 \\
(0.004)\end{array}$ & {$[0.98,0.995]$} & $\begin{array}{l}0.97 \\
(0.007)\end{array}$ & {$[0.957,0.984]$} & $\begin{array}{l}0.987 \\
(0.005)\end{array}$ & {$[0.976,0.994]$} \\
\hline $1+\chi_{\pi}$ & $\begin{array}{l}1.35 \\
(0.18)\end{array}$ & {$[1.1,1.79]$} & $\begin{array}{l}1.45 \\
(0.22)\end{array}$ & {$[1.13,1.94]$} & $\begin{array}{l}1.377 \\
(0.20)\end{array}$ & {$[1.1,1.86]$} \\
\hline$\chi_{x}$ & $\begin{array}{l}0.37 \\
(0.14)\end{array}$ & {$[0.17,0.72]$} & $\begin{array}{l}0.18 \\
(0.06)\end{array}$ & {$[0.08,0.31]$} & $\begin{array}{l}0.19 \\
(0.1)\end{array}$ & {$[0.05,0.44]$} \\
\hline$\chi_{s}$ & $\begin{array}{l}0.034 \\
(0.023)\end{array}$ & {$[-0.001,0.09]$} & $\begin{array}{c}-0.0001 \\
(0.007)\end{array}$ & {$[-0.013,0.015]$} & $\begin{array}{l}0.132 \\
(0.05)\end{array}$ & {$[0.06,0.25]$} \\
\hline$\sigma_{r}$ & $\begin{array}{l}0.56 \\
(0.02)\end{array}$ & {$[0.52,0.61]$} & $\begin{array}{l}0.56 \\
(0.02)\end{array}$ & {$[0.52,0.62]$} & $\begin{array}{l}0.70 \\
(0.02)\end{array}$ & {$[0.66,0.74]$} \\
\hline$\sigma_{e}$ & $\begin{array}{l}4.17 \\
(0.17)\end{array}$ & {$[3.85,4.53]$} & $\begin{array}{l}4.17 \\
(0.19)\end{array}$ & {$[3.83,4.58]$} & $\begin{array}{l}4.12 \\
(0.13)\end{array}$ & {$[3.88,4.40]$} \\
\hline$\sigma_{u}$ & $\begin{array}{l}0.21 \\
(0.01)\end{array}$ & {$[0.19,0.23]$} & $\begin{array}{l}0.21 \\
(0.01)\end{array}$ & {$[0.19,0.23]$} & $\begin{array}{l}0.23 \\
(0.007)\end{array}$ & {$[0.22,0.25]$} \\
\hline$\sigma_{\varepsilon}$ & $\begin{array}{c}0.02 \\
(0.001)\end{array}$ & {$[0.018,0.022]$} & $\begin{array}{c}0.02 \\
(0.001)\end{array}$ & {$[0.018,0.022]$} & $\begin{array}{l}0.046 \\
(0.001)\end{array}$ & {$[0.04,0.05]$} \\
\hline$\rho_{r}$ & $\begin{array}{l}0.39 \\
(0.05)\end{array}$ & {$[0.28,0.49]$} & $\begin{array}{l}0.36 \\
(0.06)\end{array}$ & {$[0.26,0.47]$} & $\begin{array}{l}0.44 \\
(0.04)\end{array}$ & {$[0.36,0.52]$} \\
\hline$\rho_{e}$ & $\begin{array}{l}0.24 \\
(0.05)\end{array}$ & {$[0.14,0.35]$} & $\begin{array}{l}0.24 \\
(0.05)\end{array}$ & {$[0.15,0.33]$} & $\begin{array}{l}0.31 \\
(0.05)\end{array}$ & {$[0.21,0.41]$} \\
\hline$\rho_{u}$ & $\begin{array}{l}0.26 \\
(0.06)\end{array}$ & {$[0.15,0.37]$} & $\begin{array}{l}0.25 \\
(0.05)\end{array}$ & {$[0.16,0.35]$} & $\begin{array}{l}0.15 \\
(0.04)\end{array}$ & {$[0.08,0.22]$} \\
\hline $\mathrm{g}$ & $\begin{array}{l}0.0138 \\
(0.0024)\end{array}$ & {$[0.009,0.019]$} & $\begin{array}{c}0.0148 \\
(0.0022)\end{array}$ & {$[0.01,0.019]$} & $\begin{array}{r}0.0094 \\
(0.0017)\end{array}$ & {$[0.006,0.013]$} \\
\hline$\frac{\psi}{1+\psi}$ & $\begin{array}{c}0.00064 \\
(0.0008)\end{array}$ & {$[0.000006,0.003]$} & $\begin{array}{c}0.00064 \\
(0.0008)\end{array}$ & {$[0.000006,0.003]$} & $\begin{array}{l}0.0061 \\
(0.0048)\end{array}$ & {$[0.00005,0.017]$} \\
\hline
\end{tabular}

Table 3 - Posterior Estimates: Alternative Models.

The table shows the posterior mean, standard deviations, and the 95\% Highest Posterior Density Interval. The second and third column refer to the estimate for the 1984:M1-2007:M7 sample, the fourth and fifth column to the 1984:M1-2007:M7 sample using a model with a Taylor rule that responds to expected inflation and output gap $i_{t}=\rho i_{t-1}+(1-\rho)\left[\left(1+\chi_{\pi}\right) \widehat{E}_{t} \pi_{t+1}+\chi_{x} \widehat{E}_{t} x_{t+1}+\chi_{s} s_{t-1}\right]+\varepsilon_{t}$, the sixth and seventh to the full-sample estimation of a model in which the stock price gap $s_{t}$ is assumed not to affect economic agents' expectations in (2.10). 


\begin{tabular}{|lccc|ccccc|c|}
\hline \hline & Horizon & \multicolumn{2}{c|}{ MP Shock } & \multicolumn{2}{c|}{$r_{t}^{N}$ Shock } & \multicolumn{2}{c|}{ Stock Market Shock } & \multicolumn{2}{c|}{ Inflation Shock } \\
\hline & & Pre-1979 & Post-1984 & Pre-1979 & Post-1984 & Pre-1979 & Post-1984 & Pre-1979 & Post-1984 \\
\hline Output Gap & 6 & 0.027 & 0.020 & 0.606 & 0.856 & 0.358 & 0.109 & 0.002 & 0.013 \\
& 24 & 0.156 & 0.133 & 0.425 & 0.726 & 0.408 & 0.129 & 0.004 & 0.012 \\
& $\infty$ & 0.162 & 0.257 & 0.402 & 0.569 & 0.426 & 0.162 & 0.005 & 0.012 \\
\hline Stock Price Gap & 6 & 0.034 & 0.004 & 0.028 & 0.125 & 0.930 & 0.861 & 0.001 & 0.009 \\
& 24 & 0.074 & 0.039 & 0.062 & 0.222 & 0.856 & 0.726 & 0.003 & 0.011 \\
& $\infty$ & 0.075 & 0.097 & 0.062 & 0.212 & 0.855 & 0.676 & 0.003 & 0.011 \\
\hline Inflation & 6 & 0.038 & 0.01 & 0.024 & 0.067 & 0.058 & 0.052 & 0.874 & 0.869 \\
& 24 & 0.049 & 0.028 & 0.034 & 0.096 & 0.125 & 0.075 & 0.786 & 0.798 \\
& $\infty$ & 0.050 & 0.060 & 0.035 & 0.10 & 0.128 & 0.09 & 0.781 & 0.759 \\
\hline FFR & 6 & 0.742 & 0.818 & 0.043 & 0.040 & 0.199 & 0.127 & 0.009 & 0.014 \\
& 24 & 0.429 & 0.651 & 0.072 & 0.107 & 0.483 & 0.227 & 0.009 & 0.014 \\
& $\infty$ & 0.421 & 0.635 & 0.072 & 0.120 & 0.492 & 0.231 & 0.009 & 0.013 \\
\hline \hline
\end{tabular}

Table 4 - Forecast Error Variance Decomposition. 


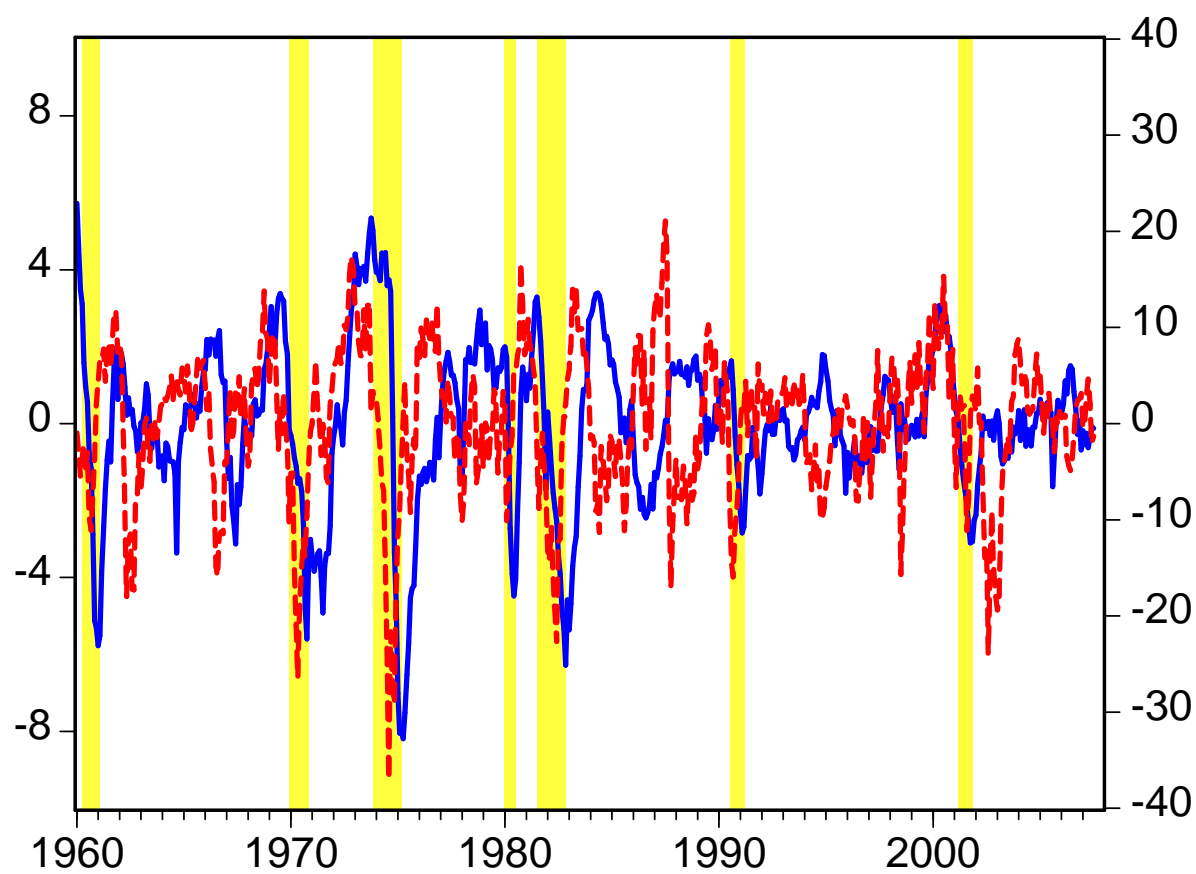

\section{- Output Gap --- Real Stock Price Gap}

Figure 1. Output Gap and Real Stock Price Gap series. Note: the series are expressed in percentage deviations from potential; the left scale refers to the output gap, right scale to the stock price gap. The light-yellow shaded areas denote NBER recession dates. 


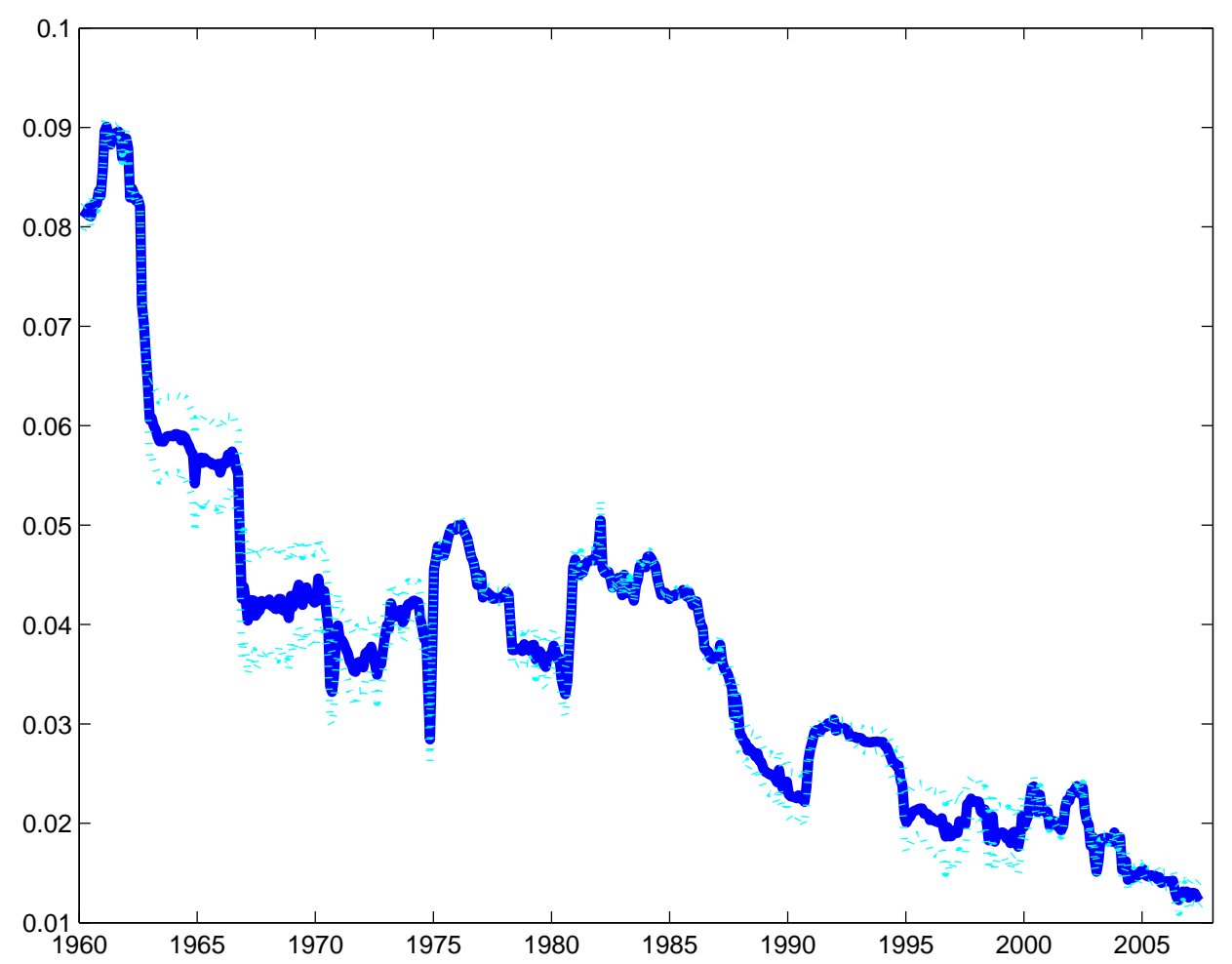

Figure 2. Agents' Beliefs: Perceived Sensitivity of the Output Gap to Stock Price Gap Movements. Note: The solid line denotes the posterior mean of beliefs across Metropolis-Hastings draws. The dotted lines denote the $2.5 \%$ and $95 \%$ error bands. 


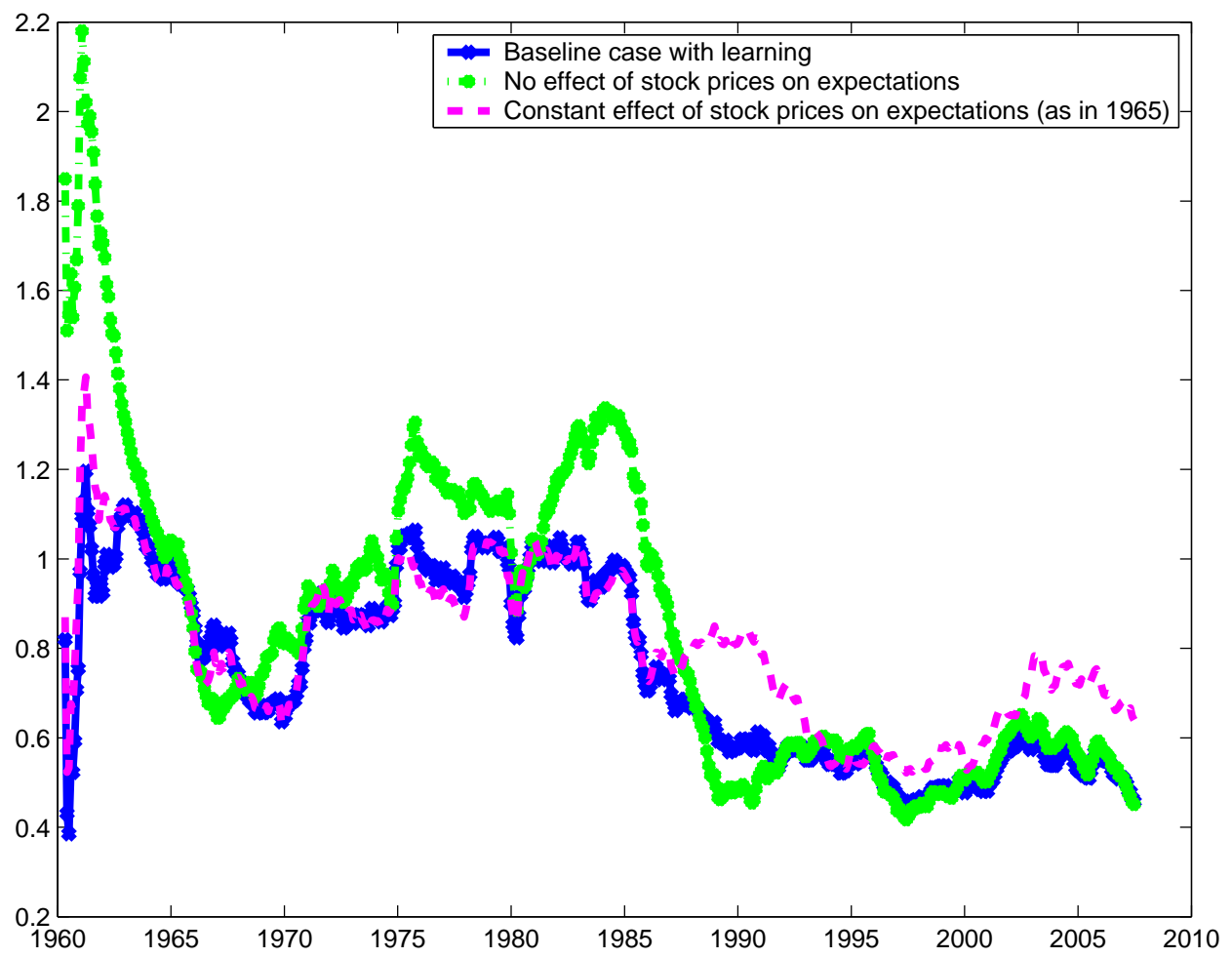

Figure 3. Rolling Root Mean Squared Error. Note: The graphs shows the rolling RMSE calculated using a window of 60 observations (for the first five years, the RMSE is recursively calculated. The baseline case refers to the agents' PLM in (2.10), the second assuming a zero effect of the real stock price gap in the agents' PLM, the third assuming a constant (large) effect of the stock price gap on output expectations, which is fixed at the agents' belief in 1965 (i.e., $b_{12}=0.056$ ) 
26

FABIO MILAN

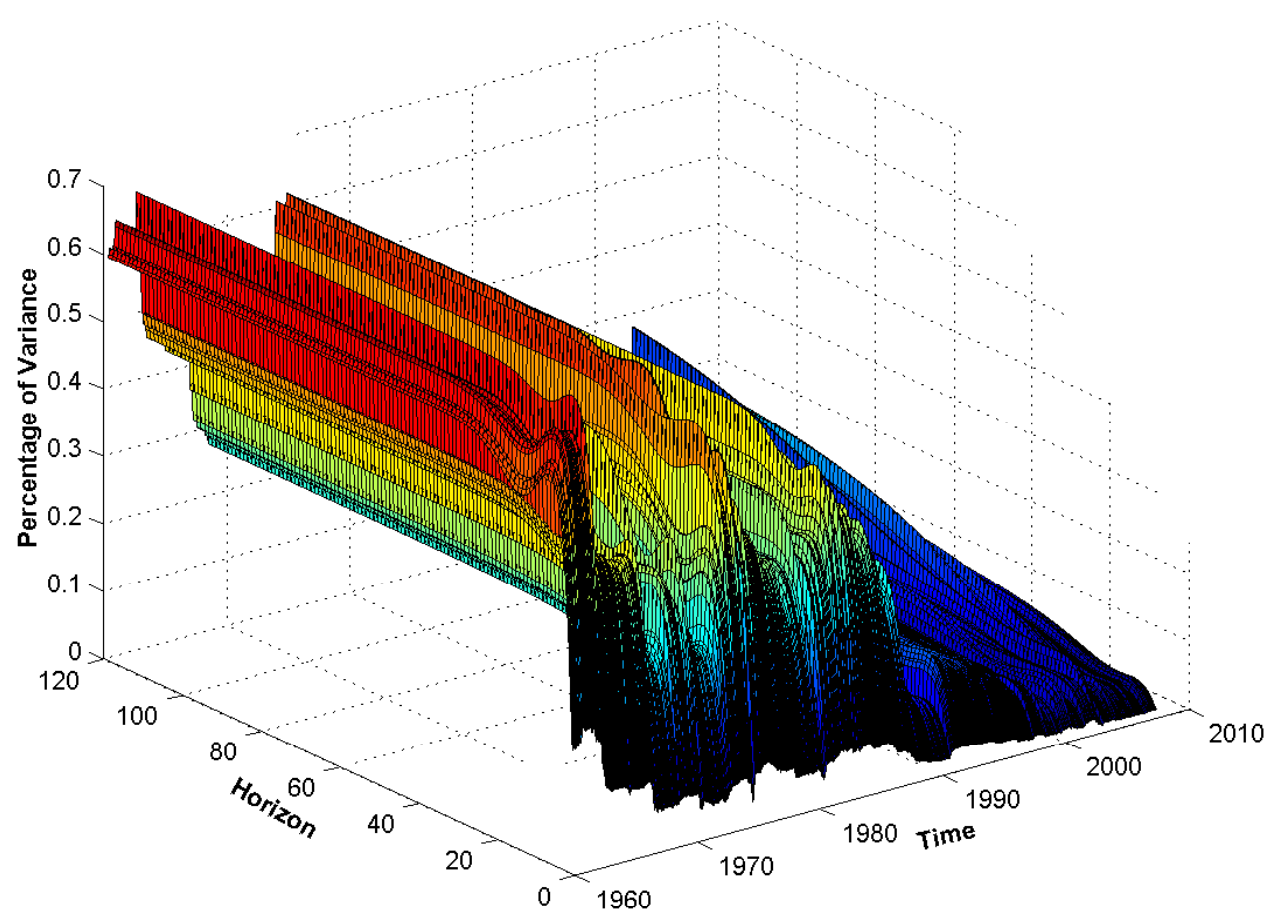

FiguRe 4. Variance Decomposition: Variance of the output gap, $x_{t}$, due to stock price gap shocks, shown across forecast horizons and over the sample. 


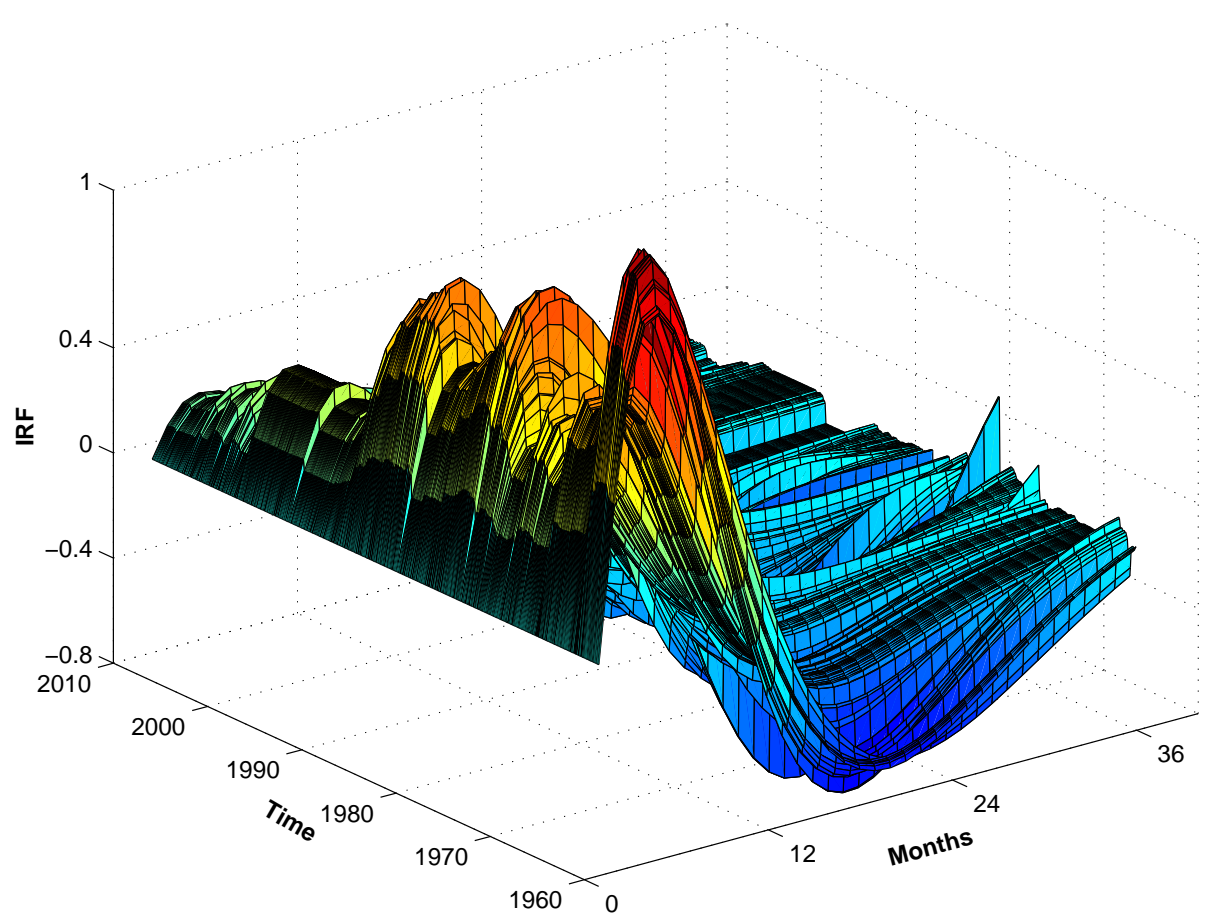

FiguRE 5. Impulse Response Function of the Output Gap to a one-standarddeviation Stock Price Gap Shock, shown across horizons and over the sample. 

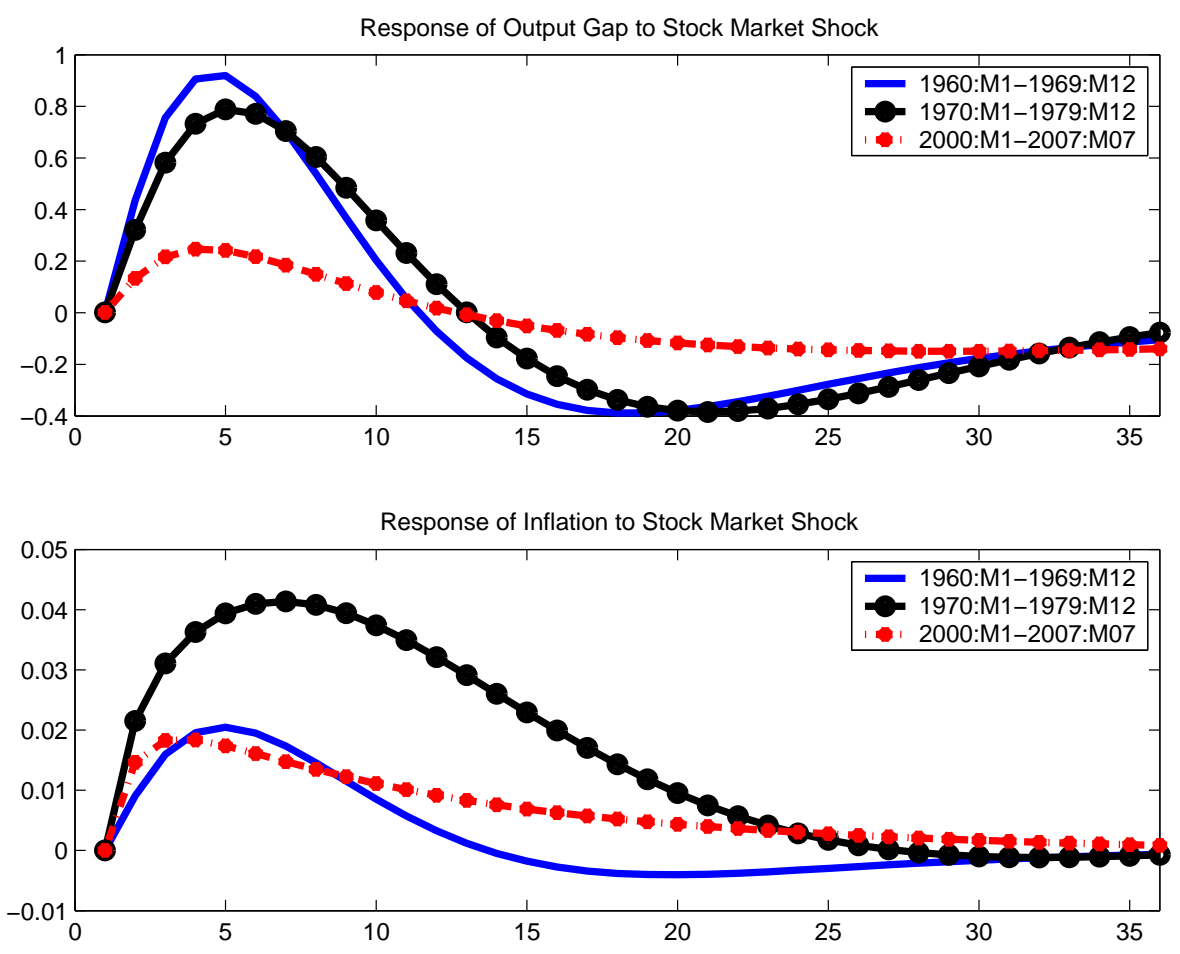

Figure 6. Impulse Response Functions of the Output Gap and Inflation to one-standard-deviation Stock Price Gap Shocks. 

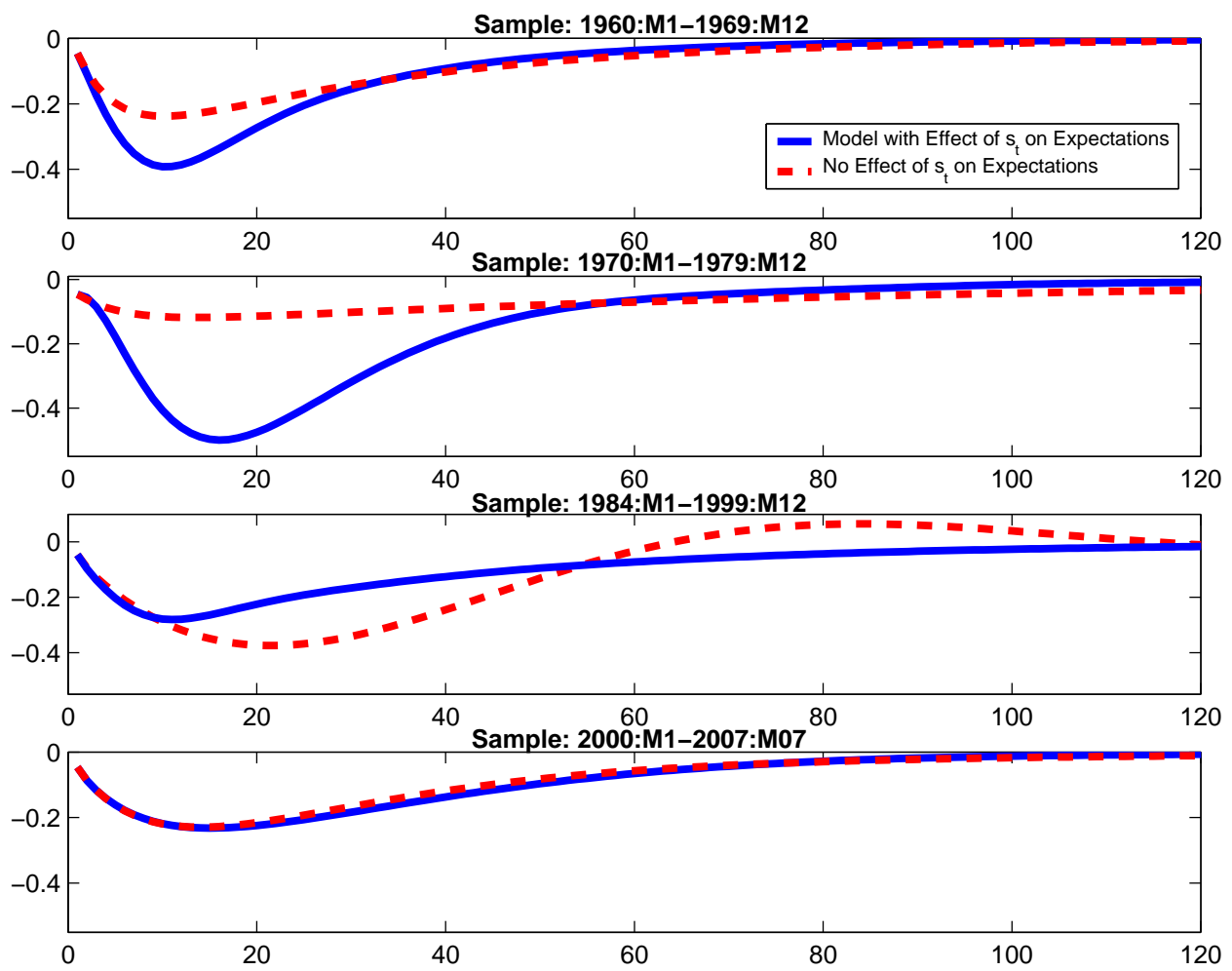

FiguRE 7. Impulse Response Functions of the Output Gap to a one-standarddeviation Monetary Policy Shock. Note: The solid line denotes the impulse responses in the baseline estimated model, which includes a direct wealth effect and allows for an effect of stock prices on expectations. The dashed line refers to an alternative model, in which the effect of stock prices on expectations is shut down. 

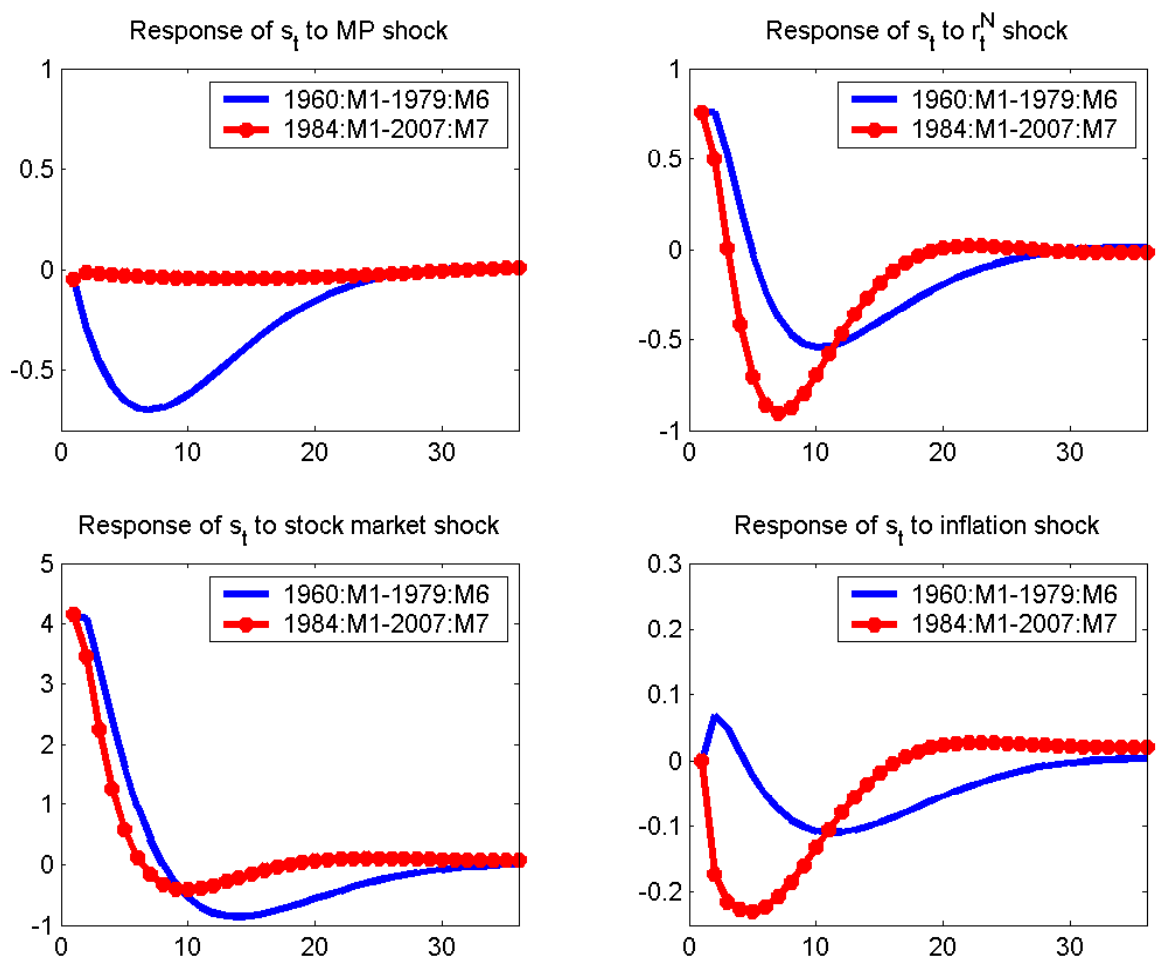

Figure 8. Impulse Response Functions of the Real Stock Price Gap to onestandard-deviation Monetary Policy, Natural Rate, Stock Market, and CostPush Shocks. 